\title{
Use of Behavior Management Techniques by Dental Practitioners During the Treatment of Pediatric Patients from Different Age Groups
}

\author{
Maria Shindova $^{1, *}$, Ani Belcheva ${ }^{1}$
}

\begin{abstract}
Objective: Behavior management is widely agreed to be a key factor in the care of children in pediatric dentistry. It is important dentists have a wide range of behavior guidance techniques to meet the needs of the individual child. To investigate the dental practitioners' use of the non-pharmacological behavior management techniques in attending pediatric dental patients from different age groups.
\end{abstract}

Methods: An anonymous, self-completed mailed survey was sent to 200 dentists. The recorded information included items on the frequency of using different non-pharmacological behavior management techniques and factors influencing their use, socio-demographic questions, working experience, specialty status. Descriptive statistics were generated to estimate demographic data and the frequency of using behavior management techniques

Results: Distraction was practiced by all participants mainly for patients less than 3 years $(43.22 \%)$. Positive reinforcement and Stop signals have been chosen for middle-aged children. One-third of practitioners selected Voice control techniques in each patient's age group. The least employment of nonpharmacological techniques by respondents was for the restraint, used mainly for the very young patients (7.63\%), and Latent inhibition, predominantly in children 6-12 years old. Almost all practitioners reported being influenced by children`s emotional state, their past dental experience and the age in the selection of a behavior management technique.

\footnotetext{
${ }^{1}$ Department of Pediatric Dentistry, Faculty of Dental Medicine, Medical University - Plovdiv, Bulgaria

* Corresponding Author

Maria Shindova mariya.shindova@gmail.com; mariya.shindova@mu-plovdiv.bg ORCID: 00000003-2996-3700

* Received: 6 May 2021 Accepted: 20 June 2021

DOI: 10.17932/EJOH.2020.022/ejoh_v02i1004
} 
Use of Behavior Management Techniques by Dental Practitioners During the Treatment of Pediatric Patients from Different Age Groups

Conclusion: The results of the present study highlighted the use of a variety of non-pharmacological behavior management techniques among dental specialists, although few acknowledged having adequate skills to apply the techniques. The choice of the technique was mainly influenced by the children`s factors.

Keywords: behavior management techniques, age, pediatric dentistry

\section{Introduction}

Behavior management is widely agreed to be a key factor in the care of children in pediatric dentistry. Therefore, it is one of the cornerstones of the specialty [1]. The child's behavior on each dental visit depends on the variables such as age, parental behavior, parental anxiety, medical history, type of dental procedure, behavior guidance and the procedural techniques followed by the dentist [2]. As the etiology of dental anxiety is multi-factorial, it is important that dentists have a wide range of behavior management techniques (BMTs) to meet the needs of the individual child and are tolerant and flexible in the implementation of these techniques [3]. The American Academy of Pediatric Dentistry (AAPD) has issued a set of guidelines on behavior guidance for pediatric dental patients [4]. BMTs have been classified as pharmacological as opposed to nonpharmacological, communicative (communication) versus advanced BMTs and universally accepted ones, as well as informal and common-sense techniques versus formal relaxation techniques [1,5]. The AAPD has classified BMTs into basic and advanced techniques. BMTs are a set of procedures employed by dental practitioners used to alleviate anxiety, establish communication, instill a positive attitude and enable performing quality oral health care safely and efficiently for children [6]. Children exhibit different attitudes and temperaments, which are influenced by their differences in physical, emotional, and social development. Thus, to communicate successfully with a child, it is necessary to understand his or her intellectual level and how cognitive processes work associated with the relevant age period. As per Jean Piaget's theory of cognitive development, a child's way of thinking about and viewing the world is quite different at the different age stages in its development [7]. Research on the association between the application of the BMTs and the proper age period of the child's development for their use can enable the pediatric dentists to better understand them and deliver improved quality of care. Few publications reporting the application of BMTs were retrieved despite its importance in creating a positive attitude towards dentistry. Therefore, the objective of the study was to investigate the dental practitioners' use of the non-pharmacological BMTs in attending pediatric dental patients from different age groups. 


\section{Methods}

The cross-sectional study consisted of an anonymous, self-completed mailed survey. Potential subjects were sent an email describing the study and inviting their participation. The participants were randomly selected from the official register of the Bulgarian Dental Organization in Plovdiv, Bulgaria. Two hundred dentists were invited to participate in the study, extrapolated using a randomized program from the complete email list of the scientific society`s members. The mail included a brief cover letter explaining the purpose of the survey. It stressed the anonymity of the survey and that the responses would be aggregated. The surveys were mailed within three weeks. The study was conducted in September 2020 and consisted of two sections, including multiple-choice and close-ended questions. Section I included demographic questions, including gender, age, work setting, experience, specialty status-general practitioner versus specialist. From section II an information concerning the frequency of using different nonpharmacological BMTs during child age periods and factors influencing the choice for their use was collected. To limit the survey to dental practitioners who provide dental care to children, the first question was 'Do you provide dental care to children at your dental office?'. In case of a negative answer, the respondent was excluded from the study.

The clinical study was conducted in accordance with the conditions and principles of the Declaration of Helsinki, the existing EU Clinical Trial Directive (EC) No. 2001/20/EC, the recommendations of the Ethical Committee at the Medical University of Plovdiv, Bulgaria and the International ethical and scientific quality standard for designing, recording and reporting trials that involve the participation of human subjects - Good Clinical Practices (GCP). Ethical approval was obtained from the University Research Ethics Committee before circulating the questionnaire (Document No.P-1371/30.04.2018).

The sample size was calculated using an online calculator (www.raosoft. com/samplesize.html). Based on the calculation with 5\% margin of error, $95 \%$ confidence level, and $80 \%$ response distribution, at least 173 dental practitioners were needed out of a total of 581 dentists involved [8]. By the end of the data collection phase, 118 completed questionnaires were collected from the participants.

The obtained data were tabulated, processed and analyzed using SPSS (Statistical Package for Social Science software) version 21.0 (IBM, USA). Descriptive statistics were generated to estimate demographic data and the frequency of using BMTs. 
Use of Behavior Management Techniques by Dental Practitioners During the Treatment of Pediatric Patients from Different Age Groups

\section{Results}

Out of the 200 surveys that were mailed, 118 subjects (59\% response rate) were included in the statistical analysis for this study. The sample size was $n=118$ dentists. Demographic information about responders and their practices is reported in Table 1.

Table 1. Demographic and practice information of survey practitioners, $n=118$

\begin{tabular}{|c|c|c|}
\hline & $\mathrm{n}$ & Percentage of responders \\
\hline \multicolumn{3}{|l|}{ Gender } \\
\hline Male & 47 & $39.8 \%$ \\
\hline Female & 71 & $60.2 \%$ \\
\hline \multicolumn{3}{|l|}{ Total years in practice } \\
\hline$<5$ years & 23 & $19.5 \%$ \\
\hline $5-10$ years & 54 & $45.8 \%$ \\
\hline $10-20$ years & 26 & $22.0 \%$ \\
\hline$>20$ years & 15 & $12.7 \%$ \\
\hline \multicolumn{3}{|l|}{ Specialty status } \\
\hline General practitioner & 69 & $58.5 \%$ \\
\hline $\begin{array}{l}\text { Another specialty, not including pediatric } \\
\text { dentistry }\end{array}$ & 40 & $33.9 \%$ \\
\hline Pediatric dentistry & 9 & $7.6 \%$ \\
\hline \multicolumn{3}{|l|}{ Location of facility } \\
\hline Urban & 113 & $95.8 \%$ \\
\hline Rural & 5 & $4.2 \%$ \\
\hline \multicolumn{3}{|l|}{ Received formal training on BMT } \\
\hline Yes & 22 & $18.6 \%$ \\
\hline No & 96 & $81.4 \%$ \\
\hline
\end{tabular}

Overall, the mean age of 118 subjects responding to this item was $36.75 \pm 9.16$ years old. Subjects were asked to indicate one of four categories of total years in practice ( $0-5$ years, 5-10 years, $10-20$ years and over 20 years). The largest group had 5-10 years of clinical experience, while the other groups were reasonably well distributed. Female respondents outnumbered males 1.5:1. 113 dentists (95.8\%) were working in urban located facilities. A large portion, $81.4 \%$, reported to have not been received formal training on BMT. 
Table 2 summarizes the usage of different BMTs for different age periods. Responses regarding the general use of BMTs were as follows: Nonverbal communication, Tell-show-do (TSD), Voice control, Positive and Negative reinforcement, Distraction and Stop signals, Modelling, Desensitization, Cognitive restructuring, Parental presence/absence, Latent inhibition, Restraint.

Table 2. Frequency and percentage of BMT for each patient's age group, $n=118$

\begin{tabular}{|c|c|c|c|c|}
\hline BMTs & $0-3$ years & $3-6$ years & $6-12$ years & $>12$ years \\
\hline $\begin{array}{l}\text { Nonverbal communica- } \\
\text { tion }\end{array}$ & $\begin{array}{l}16.95 \% \\
(20)\end{array}$ & $\begin{array}{l}9.32 \% \\
(11) \\
\end{array}$ & $\begin{array}{l}8.47 \% \\
(10)\end{array}$ & $8.47 \%(10)$ \\
\hline Tell-show-do (TSD) & $\begin{array}{l}33.89 \% \\
(40)\end{array}$ & $\begin{array}{l}51.69 \% \\
(61)\end{array}$ & $\begin{array}{l}24.58 \% \\
(29)\end{array}$ & $\begin{array}{l}22.03 \% \\
(26)\end{array}$ \\
\hline Voice control & $\begin{array}{l}22.03 \% \\
(26)\end{array}$ & $\begin{array}{l}27.12 \% \\
(32)\end{array}$ & $\begin{array}{l}30.51 \% \\
(36)\end{array}$ & $\begin{array}{l}24.58 \% \\
(29)\end{array}$ \\
\hline Positive reinforcement & $\begin{array}{l}38.14 \% \\
(45)\end{array}$ & $\begin{array}{l}62.71 \% \\
(74)\end{array}$ & $\begin{array}{l}52.54 \% \\
(62)\end{array}$ & $\begin{array}{l}49.15 \% \\
(58)\end{array}$ \\
\hline Negative reinforcement & $0.85 \%(1)$ & $5.08 \%(6)$ & $\begin{array}{l}12.71 \% \\
(15)\end{array}$ & $\begin{array}{l}13.60 \% \\
(16)\end{array}$ \\
\hline Distraction & $\begin{array}{l}43.22 \% \\
(51)\end{array}$ & $\begin{array}{l}23.73 \% \\
(28)\end{array}$ & $\begin{array}{l}15.25 \% \\
(18)\end{array}$ & $\begin{array}{l}11.86 \% \\
(14)\end{array}$ \\
\hline Stop signals & $\begin{array}{l}15.25 \% \\
(18)\end{array}$ & $\begin{array}{l}46.61 \% \\
(55)\end{array}$ & $\begin{array}{l}58.47 \% \\
(69) \\
\end{array}$ & $\begin{array}{l}52.54 \% \\
(62)\end{array}$ \\
\hline Modelling & $\begin{array}{l}11.02 \% \\
(13)\end{array}$ & $\begin{array}{l}11.02 \% \\
(13)\end{array}$ & $\begin{array}{l}26.27 \% \\
(31)\end{array}$ & $\begin{array}{l}21.19 \% \\
(25)\end{array}$ \\
\hline Desensitization & $\begin{array}{l}15.25 \% \\
(18)\end{array}$ & $\begin{array}{l}15.25 \% \\
(18)\end{array}$ & $1.69 \%(2)$ & $0.85 \%(1)$ \\
\hline Cognitive restructuring & $1.69 \%(2)$ & $2.54 \%(3)$ & $4.24 \%(5)$ & $8.47 \%(10)$ \\
\hline $\begin{array}{l}\text { Parental presence/ab- } \\
\text { sence }\end{array}$ & $\begin{array}{l}20.34 \% \\
(24)\end{array}$ & $\begin{array}{l}18.64 \% \\
(22)\end{array}$ & $\begin{array}{l}13.60 \% \\
(16)\end{array}$ & $\begin{array}{l}11.86 \% \\
(14)\end{array}$ \\
\hline Latent inhibition & - & $0.85 \%(1)$ & $3.39 \%(4)$ & $1.69 \%(2)$ \\
\hline Restraint & $7.63 \%(9)$ & - & $0.85 \%(1)$ & - \\
\hline
\end{tabular}

The majority of practitioners responded that with all aged groups, except for 0-3 years, they use: Positive reinforcement, Stop signals and Voice control. TSD was selected by $51.69 \%$ of participants to be used for 3-6 years patients. Positive reinforcement and Stop signals have been chosen for middle-aged children, about $60 \%$ indicated their use of Positive reinforcement for patients 6-12 and about 50\% employed both techniques for patients older than 12 years. Distraction techniques were mainly selected for the very young patients, with $43.22 \%$ responded using 
Use of Behavior Management Techniques by Dental Practitioners During the Treatment of Pediatric Patients from Different Age Groups

the technique for patients 0-3 years, one quarter employed it for 3-6 years, and less than $15 \%$ - in patients older than 6 years. One-third of practitioners selected Voice control techniques in each patient's age group. The least employment of non-pharmacological BMTs by respondents was for the restraint, used mainly for the very young patients $(7.63 \%)$, and Latent inhibition, predominantly in children 6-12 years old. Techniques percentages for different ages are described in table 2 .

Almost all practitioners who participated in the current study reported being influenced by children's emotional state, their past dental experience and the age in the selection of a BMT during handling of a particular child. Parents' preferences were reported by only $2.54 \%$ of the practitioners to influence their choice of a BMT (Table 3).

Table 3. Factors influencing the choice of particular BMTs while handling a child dental patient

\begin{tabular}{lll}
\hline Influencing factors & percent & $\mathrm{n}$ \\
\hline Past dental experience & $77.97 \%$ & 92 \\
\hline Oral health & $22.03 \%$ & 26 \\
\hline Emotional state & $82.20 \%$ & 97 \\
\hline Social status & $16.95 \%$ & 20 \\
\hline Medical history & $15.25 \%$ & 18 \\
\hline Child`s age & $73.73 \%$ & 87 \\
\hline Parents` dental anxiety & $33.89 \%$ & 40 \\
\hline Parents` preferences for a BMT & $2.54 \%$ & 3 \\
\hline
\end{tabular}

\section{Discussion}

The response rate to this survey (59\%) is an indication of the interest that dental practitioners have in the topic of behavior management of child dental patients. The great majority of respondents in our investigation employed communicative BMTs, particularly with children under 12 years of age. Levy and Domoto found that Positive reinforcement, Distraction and TSD were used by a high percentage of dental practitioners in the state of Washington. In contrast to the present study, they also found that Nonverbal communication in the form of touching and stroking a child's hand or arm was employed by $83 \%$ of pediatric dental practitioners [9].

AAPD indicates TSD and Positive reinforcement are two of the most successful yet simple basic BMTs which can be used with all pediatric patients regardless of their cooperation level [4]. In the present study, these two BMTs were found to be the most popular techniques in the age of 3-6 years. A recent survey of members of AAPD reported similar popularity (99\%) with both techniques 
$(4,10)$. TSD is one of the most used techniques for patients 3-8 years, as it is safe, non-invasive and being acceptable among practitioners and parents $(1,4,6,11)$. In line with the present study, Rajasekhar et al. reported that $43.1 \%$ of participants in their study opted for TSD for building rapport with children of age 4-7 years (2). As the child reaches 3-6 years, they represent objects symbolically and attain imaginary means of thinking. They are intensely curious about the dentist's office and eager to learn about the novel things around (12). Hence, explaining the treatment and allowing them to handle and test the instruments for work would be a motivating factor in managing these children (13).

Positive reinforcement was reported as highly effective in children of 6-12 years by respondents in the present study, as the child derives from a sense of the industry and accomplishment during this stage of development. Peretz et al. also consider that receiving Positive reinforcement will facilitate positive dental attitudes in pediatric dental patients and promote future dental attendance (14). However, a theme related to the suitability and the personal value attached to receiving Positive reinforcement emerged.

Stop signals were reported as the most accepted BMT by 9-11-year-old children in an exploratory study investigating children's perceptions of dental BMTs in 2013. In line with these results, the vast majority of the respondents in our research determined Signaling as the most commonly used and most effective BMT in the treatment of children during the period of middle childhood (6-12 years). There is a dearth of literature reporting its use among dental practitioners [15]. Australian dentists were the only ones to report allowing the child to exercise some form of control over the treatment. As benefits of its use, the authors considered the provision of control aiding patient's active role during treatment, relief of worry, distress and physical discomfort treatment (12).

Distraction is also a simple and effective BMT that could be used with any child, regardless of their cooperation level (4). The results of the current study are in line with other reported surveys where Distraction has been reported to be used by the majority of respondents during the treatment of children under 3 years $(13,16)$. Concerning the attitude related to Distraction, more than half of the practitioners in India have responded positively to its use during the treatment of 2-7-year-old children (2). In contrast, Nazal et al. demonstrated that the routine use of such technique is less than TSD and Positive reinforcement (17).

Although some authors in the USA and Arabian region reported highfrequency use of Voice control (92\%), in the present study only one-third of the respondents selected it for anxiety reduction during treatment of pediatric dental patients $(13,17)$. Our study corresponds with a clear trend indicating a decline in the use of Voice control among dentists (18). This is consistent with a continual 
Use of Behavior Management Techniques by Dental Practitioners During the Treatment of Pediatric Patients from Different Age Groups

decline in the acceptance of Voice control as an appropriate BMT among parents $[19,20]$ Kuhn and Allen opined that the utilization pattern of BMT has changed over the past three decades. Parents' acceptability, legal/ethical concerns, accessibility and feasibility of certain BMTs are the factors most often cited for these changes (21).

The children of age group 0-3 years are emotionally attached to their parents and depict separation anxiety. Therefore, parental presence in the dental operatory is a crucial factor among these children during treatment. Practitioners should get accustomed to this added involvement of parents and welcome the queries and concerns (22). Nonetheless, $20.34 \%$ of the respondents in the current study use the Parental presence/absence technique while treating children under 3 years. The present results show a trend indicating a decrease in the use of Parental presence/absence technique with the increasing age of patients. In Egypt, almost all practitioners $(93.10 \%)$ prefer this technique for the management of uncooperative 0-2 years patients, as the major problem in providing treatment for them are their infantile behavior and immature communication ability $(6,23)$. While in India, less than half of the respondents $(40.2 \%)$ rely on parental presence while treating children of 0-2 years (2). A cross-sectional study in 2018 indicated that dentists utilized parental absence with approximately $34 \%$ of patients from all age groups (18). Probably similar usage across all age patients` groups responds with the parental demand for presence in the operatory. Several studies have reported that contemporary parents have a clear preference to be present in the operatory for all types of dental procedures - a trend reported in various countries and cultures $(14,22)$. However, Parental absence can be an effective BMT and have high parental acceptance if discussed with parents before the treatment $(24,25)$.

In past studies, the use of physical restraint was reported by more than $80 \%$ of respondents (13). Restraint techniques are recommended in specific situations (4). A study in the Arabian region showed a wide use of protective stabilization whose results are within the range reported by members of the AAPD - $68-73 \%$ $(15,19)$. The least employment of non-pharmacological BMTs by the respondents in our study was for the restraint, used mainly for the very young patients (7.63\%) - 0-3 years. In line with the current study, the use of restraint has been reported as the least used BMT amongst UK dentists (26). The present results showed that Latent inhibition has also been used by very few practitioners mainly for patients during the period of middle childhood. The specific indications, preparation and time consumption required for such techniques are likely reasons for the low frequency of use reported in the current and a previous study (17). In 2016 Williams found that dental practitioners are least familiar with this technique, as it is a psychological technique that is not a traditional part of dental curricula (16). 
The analysis of the present results demonstrates that personal factors associated with the physical, emotional and psychological health of the child mainly influence dental practitioners' choice of BMT to be used in a particular pediatric dental patient. This indicates that the child's emotion and presenting behavior in the dental setting are important. Of the individual-level factors of the children, the previous dental experience was reported by the majority of authors to influence their choice that underlines the importance of proper child management in pediatric dentistry (27). In line with the present findings, Oredugba et al. and Kawia et al. reported that a major factor influencing the choice of BMT was also the child's age $(27,28)$. Unlike the present results, Carr et al. reported the reason for the use of most BMT to be parental influence (29). Generally, the personal factors of the child were reported by more dentists than socioeconomic status and medical history to influence their choice for a BMT to be applied.

The information of the participants collected during the study will be kept strictly confidential and will not be disclosed to third parties. Confidentiality will be guaranteed by a coded ID number, access will be granted exclusively to the study investigators.

\section{Conclusion}

The results of the present study highlighted the use of a variety of nonpharmacological BMTs among dental specialists, although few acknowledged having adequate skills to apply the techniques. Distraction is the best BMT for patients under 3 years, while Positive reinforcement was the most effective in 3-6 years old children. Almost all respondents have rated Stop signals as the most commonly used non-pharmacological BMTs for patients older than 6 years. The choice of the technique was mainly influenced by the personal factors associated with the physical and phycological health of the child.

A limitation of the present study which is worth mentioning is the small sample size. Since the responsibility rate was lower than the ideal one, it had not been possible to survey the estimated larger sample size. Therefore, the chance of assuming as true a false premise has increased.

\section{References}

1. Roberts JF, et al. Review: behavior management techniques in paediatric dentistry. Eur Arch Paediatr Dent. 2010;11:166-74. doi: 10.1007/BF03262738. PMID: 20840826.

2. Rajasekhar $\mathrm{S}$, et al. Knowledge and attitudes of dental graduates regarding the application of child psychology during the behavioral guidance of children: 
Use of Behavior Management Techniques by Dental Practitioners During the Treatment of Pediatric Patients from Different Age Groups

A cross-sectional survey of dental students. SRM J Res Dent Sci.2018;9:53. doi: 10.4103/srmjrds.srmjrds_10_18

3. Feigal RJ. Guiding and managing the child dental patien. J Dent Educ. 2001; 65:1369-77. PMID: 11780655

4. American Academy of Pediatric Dentistry. Behavior guidance for the pediatric dental patient. The Reference Manual of Pediatric Dentistry. Chicago, Ill.: American Academy of Pediatric Dentistry. 2020;292-310.

5. Folayan MO, Idehen E. Factors influencing the use of behavioral management techniques during child management by dentists. J Clin Pediatr Dent. 2004; 28:155-61. doi: 10.17796/jcpd.28.2.18w2v457t8878p69.

6. Kanzel S, et al. Behavior Management Techniques Adopted by Pediatric Dentists in Egypt. 2019. DOI:10.21203/rs.2.17100/v1

7. Badakar C,et al. Evaluation of the Relevance of Piaget's Cognitive Principles among Parented and Orphan Children in Belagavi City, Karnataka, India: A Comparative Study. Int J Clin Pediatr Dent. 2017;10:346-350. doi: 10.5005/ jp-journals-10005-1463.

8. Dillman DA, Smyth JD, Christian LM. Internet, mail and mixed-mode surveys. The tailored design method. 3rd ed. New Jork: John Wiley \& Sons, 2009.

9. Levy RL, Domoto PK. Current techniques for behavior management: a survey. Pediatr Dent. 1979;1:160-4. PMID: 162216

10. Vishwakarma AP,et al.Effectiveness of two different behavioral modification techniques among 5-7-year-old children: A randomized controlled trial. J Indian Soc Pedod Prev Dent. 2017;35:143-149. doi: 10.4103/ JISPPD. JISPPD_257_16.

11. Daghamin SA, et al. Behavior Management Techniques in Pediatric Dentistry: How Well are they Accepted?. Acad J Ped Neonatol. 2017; 5: 555722. doi: 10.1007/BF03262738.

12. Adair SM, et al. A survey of members of the American Academy of Pediatric Dentistry on their use of behavior management techniques. Pediatr Dent. 2004;26:159-66. PMID: 15132279.

13. Wright FA, Giebartowski JE, McMurray NE. A national survey of dentists' management of children with anxiety or behaviour problems. Aust Dent J. 1991;36:378-83. DOI: 10.1111/j.1834-7819.1991.tb01361.x

14. Peretz B,et al. Child-management techniques. Are there differences in the 
way female and male pediatric dentists in Israel practice? Braz Dent J. 2003;14:82-6. doi.org/10.1590/S0103-64402003000200002.

15. Davies EB, et al. An exploratory study investigating children's perceptions of dental behavioural management techniques. Int J Paediatr Dent. 2013;23:297309. doi: 10.1111/ipd.12007.

16. Williams KA, et al. Assessing the Attitudes and Clinical Practices of Ohio Dentists Treating Patients with Dental Anxiety. Dent J (Basel). 2016;4:33. DOI: $10.3390 / \mathrm{dj} 4040033$

17. Nazzal, H.,et al.The use of behaviour management techniques amongst dentists working in the Arabian region:a cross-sectional survey study. Eur Arch Paediatr Dent. 2020;22:375. doi: 10.1007/s40368-020-00560-8.

18. Wells $\mathrm{MH}$, et al. Usage of Behavior Guidance Techniques Differs by Provider and Practice Characteristics. Pediatr Dent. 2018;40:201-208. PMID: 29793567

19. Eaton JJ,et al.Attitudes of contemporary parents toward behavior management techniques used in pediatric dentistry. Pediatr Dent. 2005;27:107-13. PMID: 15926287

20. Strange DM. The evolution of behavior guidance: a history of professional, practice, corporate and societal influences. Pediatr Dent. 2014;36:128-31. PMID: 24717750.

21. Kuhn BR, Allen KD. Expanding child behavior management technology in pediatric dentistry: a behavioral science perspective. Pediatr Dent. 1994;16:13-7. PMID: 8015936.

22. Shroff S, Hughes C, Mobley C. Attitudes and preferences of parents about being present in the dental operatory. Pediatr Dent. 2015;37:51-5. PMID: 25685974.

23. Cunha RF,et al. Longitudinal behavioral analysis during dental care of children aged 0 to 3 years. Braz Oral Res. 2009;23:302-6. doi: 10.1590/ s1806-83242009000300013.

24. Boka V,et al. Parental acceptance of behaviour-management techniques used in paediatric dentistry and its relation to parental dental anxiety and experience. Eur Arch Paediatr Dent. 2014;15:333-9. doi: 10.1007/ s40368014-0119-y. Epub 2014 Mar 28.

25. Kotsanos N,et al. Parental presence versus absence in the dental operatory: a technique to manage the uncooperative child dental patient. Eur J Paediatr Dent. 2005;6(3):144-8. PMID: 16216095. 
Use of Behavior Management Techniques by Dental Practitioners During the Treatment of Pediatric

Patients from Different Age Groups

26. Crossley ML, Joshi G. An investigation of paediatric dentists' attitudes towards parental accompaniment and behavioural management techniques in the UK. Br Dent J. 2002;192:517-21. doi: 10.1038/sj.bdj.4801416. PMID: 12047123.

27. Kawia HM,et al. Application of Behavior Management Techniques for Paediatric Dental Patients by Tanzanian Dental Practitioners. Open Dent J. 2015;9:455-61. doi: 10.2174/1874210601509010455.

28. Oredugba FA, Sanu OO. Behavior Management Techniques Employed by Nigerian Dentists for their Child Patients.Pesquisa Brasileira em Odontopediatria e Clínica Integrada. 2009;9:271-276. available at: https:// www.redalyc.org/articulo.oa?id=63712843003.

29. Carr KR,et al. Behavior management techniques among pediatric dentists practicing in the southeastern United States. Pediatr Dent. 1999;21:347-53. PMID: 10509336. 